\title{
Vertical Transport and Photochemistry in the Terrestrial Mesosphere and Lower Thermosphere (50-120 km)
}

\author{
MARK Allen and YuK L. YUNG \\ Division of Geological and Planetary Sciences, California Institute of Technology, Pasadena, California 91125
}

\author{
JOE W. WATERS
}

Jet Propulsion Laboratory, Califormia Institute of Technology, Pasadena, California 91003

\begin{abstract}
The coupled effects of kinetics, solar cycle flux variations and vertical transport on the distribution of long-lived hydrogen-carbon-oxygen compounds in the terrestrial mesosphere and lower thermosphere are studied using a one-dimensional aeronomy model. The calculations account for the important chemical reactions and use rocket measurements of the solar flux at solar minimum and maximum. Photodissociation rates appropriate for the mesosphere are determined with a spherical shell atmosphere formalism; detailed corrections for the $\mathrm{O}_{2}$ Schumann-Runge bands and the temperature dependence of the $\mathrm{CO}_{2}$ cross sections are ussed. Then an eddy diffusion profile is derived which gives agreement with the Aladdin 74 mass spectral measurements of atomic $\mathrm{O}, \mathrm{O}_{2}, \mathrm{CO}_{2}$, and $\mathrm{Ar}$ in the lower thermosphere and observations of the $\mathrm{O}_{3}$ minimum at $\sim 80 \mathrm{~km}$. The $115 \mathrm{GHz}$ CO radio emission line computed for the $\mathrm{CO}$ mixing ratio profile predicted with the new eddy diffusion profile compares well with recent observations of $W$. $\mathrm{J}$. Wilson. Differences between the calculated $\mathrm{CO}$ mixing ratio profile and previous theoretical and observational determinations are discussed. Our derived eddy diffusion profile has a sudden decrease at $92 \mathrm{~km}$ which is necessary to produce the atomic $O$ peak at $98 \mathrm{~km}$ that appears in the Aladdin 74 measurements. This stagnant region apparently is a recurrent or persistent feature of the upper atmosphere since an atomic $O$ peak around $98 \mathrm{~km}$ has been seen by different techniques in different seasons over several years. Slow eddy diffusion in the lower thermosphere through the homopause was also the conclusion of earlier $\mathrm{Ar} / \mathrm{N}_{2}$ rocket measurements studies. The analytic approach of this paper could be used in the future to monitor variations in middle atmosphere dynamics, if regularly conducted simultaneous observations of various groups of species were available.
\end{abstract}

\section{INTRODUCTION}

The chemical composition of the terrestrial mesosphere and lower thermosphere $(-50-120 \mathrm{~km}$ altitude) reflects the coupled effects of solar radiation, chemical kinetics, and mass transport. An understanding of the relative importance of each of these factors will improve our knowledge of what changes in the middle atmosphere might result from variations in these driving forces and in turn will enable observations of changes in the chemical composition to be used to monitor the variability of the solar radiation field and mass transport rates (the kinetic rate constants being 'invariable').

Mount et al. [1980] report the results of rocket measurements of the solar spectrum near solar maximum and compare them with similar observations taken around solar minimum. At certain wavelengths below $1900 \AA$, the intensity variation over the 11-year solar cycle is as much as a factor of two. Frederick [1977] has shown that smaller scale solar variation (over a 28-day cycle) causes perturbations in the abundances of odd-oxygen compounds in the mesosphere. Changes due to the 11-year solar cycle therefore will be very significant. High altitude observations of the solar radiation field, in principle, could be done sufficiently frequently so that correct values would be available for model comparisons with atmospheric data.

As will be seen in this paper, the chemistry of the neutral atomic and molecular species containing hydrogen, carbon, and oxygen can be well described by $\sim 35$ reactions. (The photochemistry of nitrogen has not been included.) This is to be compared with stratospheric models that require 150 or more reactions for an adequate description. The fewer reactions in

Copyright ( 1981 by the American Geophysical Union. the mesospheric model allow more straightforward analyses of the dependence of model results on the rate constants.

Least well known is mass transport in the mesosphere and lower thermosphere. The altitude profiles of species with chemical lifetimes close to the timescales for vertical transport will directly reflect the magnitude of the dynamical processes. In turn, the vertical profiles of species strongly coupled to these long-lived constituents will also reflect transport processes. Since the radiation field and the chemistry are or can be known with reasonable confidence, the model results for transport-sensitive species can be compared with observations to place constraints on the transport parameters.

Given the limitations of current computers, one-dimensional numerical models are best able to explore the coupling of transport and a complex chemical reaction network. In a one-dimensional photochemical model, the effect of vertical transport is conveniently parameterized by a set of eddy diffusion coefficients $K(z)$. Eddy diffusion rates may be directly connected to the nature of turbulence generated by the breakdown of gravity waves and tides [Lindzen, 1980]. The magnitude of $K(z)$ can be deduced from the study of long-lived tracer species [e.g., Hunten, 1975]. Between the tropopause and $40 \mathrm{~km}$, our knowledge of $K(z)$ is based on studies of the distribution of radioactive nuclei, $\mathrm{CH}_{4}, \mathrm{~N}_{2} \mathrm{O}$, and chlorofluoromethanes [Wofsy and McElroy, 1973; Hunten, 1975; Johnston et al., 1976; NAS, 1976; Schmeltekopf et al., 1977]. Until recently, experimental difficulties limited the amount of tracer observations in the mesosphere and our knowledge of $K(z)$ between 40 and $100 \mathrm{~km}$. Analyses of rocket mass spectral data for the thermosphere have used (1) the $\mathrm{O} / \mathrm{O}_{2}$ concentration ratio at $100 \mathrm{~km}$ to yield a value for $K(z)$ of $4 \times 10^{6} \mathrm{~cm}^{2} \mathrm{~s}^{-1}$ [Colegrove et al., 1965]; (2) the $\mathrm{Ar} / \mathrm{N}_{2}$ ratio at $120 \mathrm{~km}$ to deter- 
mine the turbopause altitude [von Zahn, 1970] which in turn results in a value of $4 \times 10^{5} \mathrm{~cm}^{2} \mathrm{~s}^{-1}$ for $K(2)$ [Hunten, 1975]; and (3) the helium density at $500 \mathrm{~km}$ to get a value of $1.8 \times$ $10^{6} \mathrm{~cm}^{2} \mathrm{~s}^{-1}$ for $K(z)$ in the lower thermosphere. In most studies, the magnitude of $K(z)$ above $80 \mathrm{~km}$ is assumed to be constant. Hunten [1975], for example, reviews the $K(z)$ determinations just enumerated and suggests a value of $1 \times 10^{6} \mathrm{~cm}^{2} \mathrm{~s}^{-1}$ for $K(z \geq 80 \mathrm{~km})$.

The different values reported for $K(z)$ in the lower thermosphere may reflect real variations in $K(z)$ since the different analyses used measurements made at different places and times. Moreover, the various tracer species are driven by slightly different transport processes, the normalization of such differences being somewhat difficult. However, a mass spectrometer rocket flight during the Aladdin 74 program simultaneously measured density profiles of $\mathrm{N}_{2}, \mathrm{O}_{2}, \mathrm{O}, \mathrm{Ar}$, and $\mathrm{CO}_{2}$ in the lower thermosphere [Trinks et al., 1978; Trinks and Fricke, 1978], which can be used to determine $K(z)$ consistent with many species. Microwave measurements of the mesospheric distribution of CO [Waters et al., 1976; Goldsmith et al., 1979; W. J. Wilson, private communication, 1979] and $\mathrm{H}_{2} \mathrm{O}$ [Radford et al., 1977; Waters et al., 1980; S. Deguchi and D. O. Muhleman, private communication, 1980] also allow the derivation of $K(z)$ for the mesosphere. Having compiled an updated model of hydrogen-carbon-oxygen upper atmosphere chemistry and having accounted for solar cycle flux variations, we used a one-dimensional computer model to explore the consequences of a range of eddy diffusion profiles to find a profile that would be consistent with the previously mentioned observations of tracer species in the mesosphere and lower thermosphere.

\section{MESOSPHERE/LOWER THERMOSPHERE MODEL}

We have developed a general one-dimensional planetary atmosphere computer program that solves the continuity equation for a species $i$,

$$
\frac{\partial n_{i}}{\partial t}+\frac{\partial \phi_{i}}{\partial z}=P_{i}-L_{i}
$$

where $n_{i}, \phi_{i}, P_{i}$ and $L_{i}$ are the concentration, vertical flux, production and loss rates of species $i$ at altitude $z$. Both steady state calculations $\left(\partial n_{t} / \partial t=0\right.$, in which case $P_{i}$ and $L_{i}$ can be diurnally averaged quantities) and time-dependent calculations $\left(\partial n_{t} / \partial t \neq 0\right.$, in which case $P_{i}$ and $L_{i}$ may follow the diurnal variation of the solar radiation field) can be performed. The transport terms include eddy, molecular, and thermal diffusion [Banks and Kockarts, 1973]. The calculations use numerical techniques similar to those described by Logan et al. [1978].

For the results reported in this paper, background atmospheres appropriate for $30^{\circ} \mathrm{N}$ July and midlatitude spring/fall were used to be consistent with the time and location of different observations. Below $80 \mathrm{~km}$ the profiles for total density, molecular nitrogen, and temperature were taken from the U.S. Standard Atmosphere Supplements (1966). The background atmosphere above $90 \mathrm{~km}$ is critically important. The results of in situ observations of the thermosphere (for example, Trinks et al. [1978]) usually differ from the theoretical profiles since theoretical models do not account for atmospheric dynamic disturbances such as tides and gravity waves. Therefore we used the Aladdin 74 total density and molecular nitrogen mass spectrometer measurements of Trinks et al.
[1978] to define the background atmosphere above $90 \mathrm{~km}$. The background atmosphere between 80 and $90 \mathrm{~km}$ was chosen to smoothly match the 80 and $90 \mathrm{~km}$ values. A derivation of the temperature profile used above $80 \mathrm{~km}$ is described in the appendix.

Our chemical model includes the chemistry and transport of the major nonnitrogen chemical species in the altitude range 50-120 km: $\mathrm{O}, \mathrm{O}\left({ }^{1} D\right), \mathrm{O}_{2}, \mathrm{O}_{3}, \mathrm{H}, \mathrm{H}_{2}, \mathrm{OH}, \mathrm{H}_{2} \mathrm{O}, \mathrm{HO}_{2}$, $\mathrm{H}_{2} \mathrm{O}_{2}, \mathrm{CO}, \mathrm{CO}_{2}, \mathrm{CH}_{4}$, and Ar. Listed in Table $\mathrm{l}$ are the important reactions governing the chemistry of these species. In most cases, the kinetic rate constants are taken directly from the sources referenced. However, in another of our middle atmosphere studies (M. Allen and Y. L. Yung, in preparation, 1981), we found that, to better fit the observed $O_{3}$ minimum at $\sim 80 \mathrm{~km}$, the values for $k_{14}, k_{15}, k_{18}, k_{28}$, and $k_{30}$ needed to be adjusted within the reported estimated uncertainty range of the laboratory values. Those adjusted values were used here. Since Klais et al. [1980] and others show that the rate constant for three-body recombination of $\mathrm{O}$ and $\mathrm{O}_{2}$ to form $\mathrm{O}_{3}$ depends on the nature of the third body, we include separately recombination with $\mathrm{O}_{2}$ and $\mathrm{N}_{2}$ as 'third bodies.' Since atomic $\mathrm{O}$ becomes more abundant than $\mathrm{O}_{2}$ above $\sim 106 \mathrm{~km}$, a separate reaction in which atomic $O$ is the third body is included and the rate constant $k_{13}$ is set equal to that for $\mathrm{O}_{2}$-mediated recombination.

The model used a solar flux adjusted for the season, latitude, and phase of the solar cycle appropriate for each set of measurements which we analyzed. The solar maximum and minimum flux values reported by Mount et al. [1980] were used. The radiative transfer calculations are for a spherical shell atmosphere with the optical opacity due to the photodissociation of molecular oxygen and ozone. Radiative transfer in the $\mathrm{O}_{2}$ Schumann-Runge bands (1750-2000 $\AA$ ) is complicated and, if not handled properly, will result in errors in the photodissociation rates of species sensitive to radiation in this range. A number of papers, most recently, Frederick and Hudson $[1980 a, b]$ and Nicolet and Peetermans [1980], have done detailed studies of this problem. We used a simple parametrization of $\mathrm{O}_{2}$ Schumann-Runge band cross sections that yield Schumann-Runge band transmission and $\mathrm{O}_{2}$ photodissociation values in good agreement with those from more complicated calculations of Frederick and Hudson [1980a, b]. The $\mathrm{H}_{2} \mathrm{O}$ Lyman alpha dissociation rate has been modified in accordance with Frederick and Hudson [1980a]. We account for the reported wavelength-dependent temperature variation of $\mathrm{CO}_{2}$ photodissociation cross sections [DeMore and Patapoff, 1972] as follows (W. B. DeMore, private communication, 1979):

$$
\begin{gathered}
\sigma(\lambda, T) / \sigma(\lambda, 298)=\{1-[P(\lambda) / 100]\}^{298-T} \\
P(\lambda)=0.5+5 \times 10^{-3}(\lambda-1740 \AA) \quad \lambda \geq 1640 \AA
\end{gathered}
$$

where $\sigma(\lambda, T)$ is the cross section at temperature $T$ and wavelength $\lambda$ and the wavelength-dependent percentage change $P(\lambda)$ is an increasing function of wavelength and is assumed to be zero for $\lambda<1640 \AA$.

The numerical calculations were performed for the altitude range $40-130 \mathrm{~km}$. Below $50 \mathrm{~km}$, however, $\mathrm{ClO}_{x}$ and $\mathrm{NO}_{x}$ are important in the chemistry of odd oxygen [Frederick, 1980], so our results apply only above $50 \mathrm{~km}$ since we do not include such chemical cycles. The lower boundary for the calculations was set at $40 \mathrm{~km}$ because of the availability of upper stratosphere observational results for the more abundant species. 
TABLE 1. Reactions and Chemical Rate Constants Used in Model

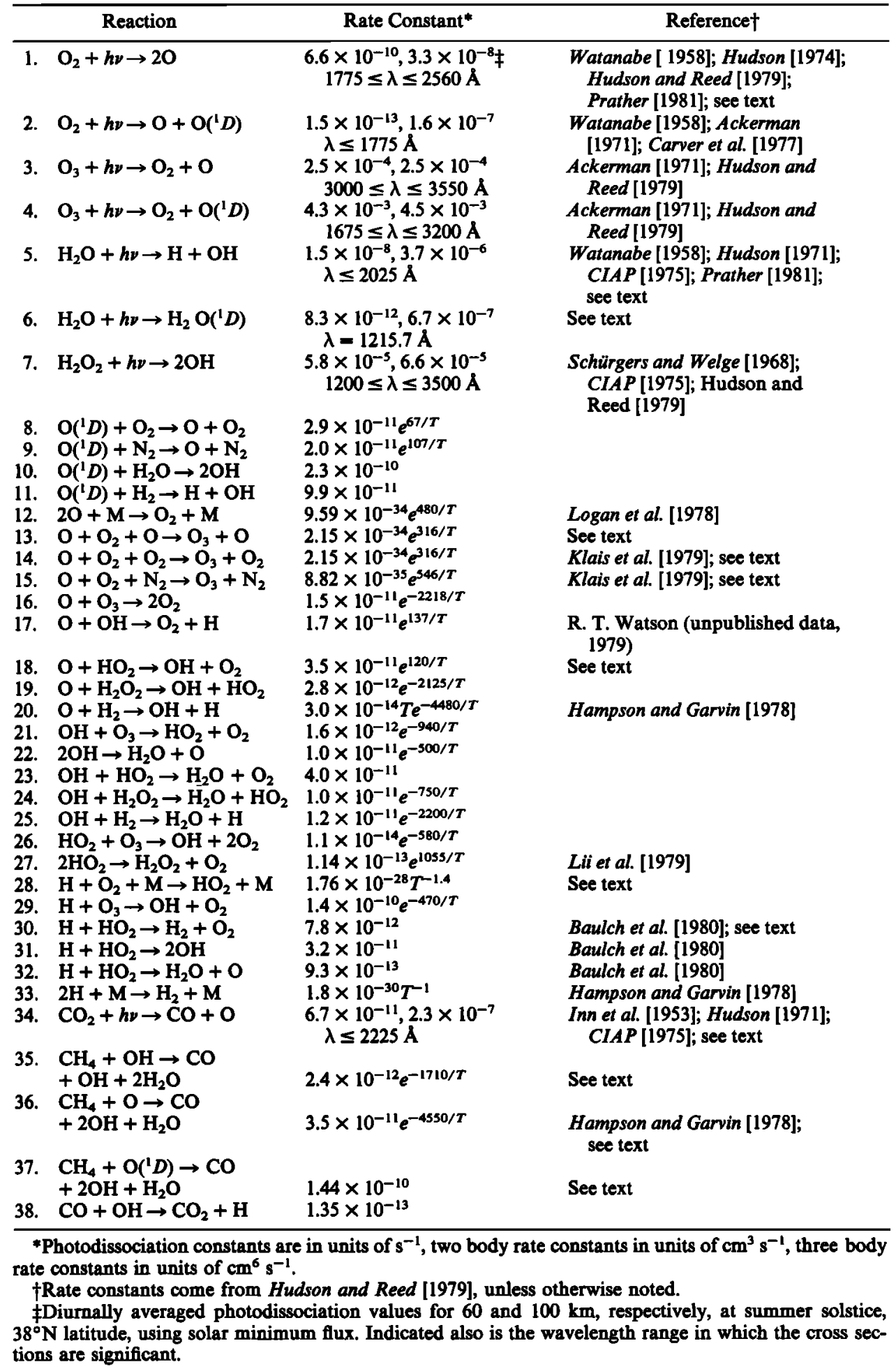

The lower (40 km) boundary conditions for $\mathrm{O}_{2}, \mathrm{CO}_{2}$, and $\mathrm{Ar}$ are the tropospheric mixing ratios of $0.21,3.3 \times 10^{-4}$, and 9.34 $\times 10^{-3}$, respectively [McElroy, 1976], and for $\mathrm{H}_{2}, \mathrm{CO}$, and $\mathrm{CH}_{4}$ are mixing ratios of $5 \times 10^{-6}$ [Ehhalt et al., 1975], $1 \times$ $10^{-8}$ [Farmer et al., 1980], and $3 \times 10^{-7}$ (an average of Ehhalt et al. [1972], Ehhalt et al. [1975], and Farmer et al. [1980]), respectively. Model calculations were run with mixing ratios for $\mathrm{H}_{2} \mathrm{O}$ of 5 and $7 \mathrm{ppm}$, a range of values that is consistent with
Farmer et al. [1980] and Waters et al. [1980]. All other species, being short lived, are in local photochemical equilibrium, so their vertical fluxes at $\mathbf{4 0} \mathbf{~} \mathbf{m}$ were set equal to zero. The upper boundary at $130 \mathrm{~km}$ was chosen to allow for accurate modeling of the region of the homopause. Molecular oxygen flows upward through the $130 \mathrm{~km}$ boundary, is photodissociated, and returns below $130 \mathrm{~km}$ as atomic oxygen. A velocity boundary condition for $\mathrm{O}_{2}$ was calculated assuming that the 
upward flux (velocity times abundance of $\mathrm{O}_{2}$ at $130 \mathrm{~km}$ ) is equal to the column $\mathrm{O}_{2}$ photodissociation rate above $130 \mathrm{~km}$. The downward flux of atomic $O$ was set equal to twice the upward $\mathrm{O}_{2}$ flux. The upward flow of carbon in the form of $\mathrm{CO}_{2}$ and its downward return as $\mathrm{CO}$ are similar; a velocity boundary condition was set for $\mathrm{CO}_{2}$ and the downward flux of $\mathrm{CO}$ was equated to the column $\mathrm{CO}_{2}$ photodissociation rate. A velocity boundary condition for $\mathrm{H}_{2} \mathrm{O}$ was used assuming that an upward flux of $\mathrm{H}_{2} \mathrm{O}$ at $130 \mathrm{~km}$ is needed to compensate for its loss above. The boundary conditions for $\mathrm{H}$ and $\mathrm{H}_{2}$ were the maximum diffusion velocities [Banks and Kockarts, 1973]. All other species are in local photochemical equilibrium, so their vertical fluxes were set equal to zero.

The transport processes incorporated in the model are eddy, molecular, and thermal diffusion. Derivation of the altitude dependence of the eddy diffusion coefficients is a goal of this work. A systematic tabulation of the available measurements of molecular diffusion is presented by Mason and Marrero [1970]. When air is the background gas, the diffusion coefficients for a variety of species of different mass are inversely related to the $\mathrm{H}_{2}$ diffusion coefficient by the square root of mass. This generalization is used in our model. The thermal diffusion parameters are $-0.27,-0.39$, and -0.31 for $\mathrm{O}, \mathrm{H}$, and $\mathrm{H}_{2}$, respectively, and zero for all other species [Keneshea et al., 1979].

\section{Derivation OF EDDY Diffusion PROFILE}

A number of different models were used in the calculations to be discussed (see Table 2). The standard case, model 1 , is a diurnally averaged calculation with a $7 \mathrm{ppm} \mathrm{H}_{2} \mathrm{O}$ mixing ratio at $40 \mathrm{~km}$ and a background atmosphere and radiation field chosen to simulate the circumstances of the Aladdin 74 measurements. One diurnal calculation, model 2, was performed to compare with the standard case. A drier atmosphere for which the $\mathrm{H}_{2} \mathrm{O}$ mixing ratio at $40 \mathrm{~km}$ was fixed at $5 \mathrm{ppm}$ was tried in one calculation, model 3. The effect of increasing the solar flux to solar maximum values was investigated (model 4). Finally, there was a calculation appropriate for the time and place of W. J. Wilson's CO measurements (model 5).

The calculated chemical lifetimes (model 1) of the major neutral nonnitrogen-containing species are shown in Figure 1. Since argon is chemically inert, its lifetime is infinite and therefore not shown. The lifetimes of all species are longer than a day, except for atomic $O$ below $86 \mathrm{~km}$. This permits accurate calculations of their abundances using a diurnally averaged model, using properly diurnally averaged photodissociation rate constants and assuming that the diurnally averaged production and loss rates (due to diurnally averaged concen- trations) are equal to daily averages of rates using diumal concentrations. A comparison of midnight and noon results of model 2 and the model 1 results for these long-lived species reveals, at most, $2 \%$ differences among these sets of data.

Also in Figure 1, the time scale for species-independent transport by eddy diffusion

$$
\tau_{E}(z)=H^{2}(z) / K(z)
$$

is compared with molecular diffusion time scales

$$
\tau_{D}(i, z)=H^{2}(z) / D(i, z)
$$

where $H(z), K(z)$, and $D(i, z)$ are the mean atmosphere scale height, eddy diffusion coefficient, and molecular diffusion coefficient for species $i$, respectively, at altitude $z$. The $K(z)$ used is the best fit profile (Figure 2) whose derivation is described later.

Below $\sim 100 \mathrm{~km}$, eddy diffusion dominates mass transport. Then the mixing ratio of a species will remain constant over an altitude range in which its chemical lifetime $\tau_{C}(i, z)$ is more than a factor of five larger than the transport time scale $\tau_{E}(z)$. But above $\sim 100 \mathrm{~km}$, the various molecular diffusion time scales become less than $\tau_{E}(z)$, thus resulting in different vertical abundance profiles because of the different diffusion velocities of each species. Therefore the $100 \mathrm{~km}$ level is the homopause, below which the 'chemically inert' species have constant mixing ratios and above which separation occurs due to different molecular diffusion rates. This explains the profiles of $\mathrm{O}_{2}, \mathrm{CO}_{2}$, and $\mathrm{Ar}$ in the lower thermosphere. The homopause altitudes individually derived from these different species may differ due to the molecular diffusion variability and the resulting sampling of eddy diffusion rates at different altitude levels.

Below the homopause, when the chemical lifetime of a species is within a factor of five of $\tau_{E}(z)$, the eddy diffusion profile strongly influences the abundance profile of the species. Such is the case for atomic $\mathrm{O}$ and $\mathrm{H}_{2} \mathrm{O}$ in the lower thermosphere and $\mathrm{CO}$ and $\mathrm{H}_{2} \mathrm{O}$ in the mesosphere. At the mesopause ( $\sim 80$ $\mathrm{km}), \mathrm{O}_{3}$ is in photochemical equilibrium $\tau_{C}\left(\mathrm{O}_{3}, 80\right) \ll \tau_{E}(80)$, but its concentration is directly proportional to the mesopause atomic $O$ abundance which is controlled by eddy diffusion. Thus $\mathrm{O}_{3}$ at the mesopause is an indirect monitor of vertical mass transport.

The eddy diffusion profile in model 1 was varied to give results which fit the measured profiles of $\mathrm{O}, \mathrm{O}_{2}, \mathrm{CO}_{2}$, and $\mathrm{Ar}$ above $90 \mathrm{~km}$ [Trinks et al., 1978; Trinks and Fricke, 1978]. As the $\mathrm{O}_{3}$ minimum at $80 \mathrm{~km}$ is affected by the downward transport of atomic $\mathrm{O}$ and the upward transport of $\mathrm{H}_{2} \mathrm{O}$ (M. Allen and Y. L. Yung, in preparation, 1981), the eddy diffusion profile was adjusted to minimize the calculated value for $\mathrm{O}_{3}$ at

\begin{tabular}{|c|c|c|c|c|c|c|}
\hline \multirow[b]{2}{*}{ Model } & \multirow[b]{2}{*}{$\begin{array}{l}\text { Background } \\
\text { Atmosphere* }\end{array}$} & \multicolumn{3}{|c|}{ Solar Radiation Parameters } & \multirow{2}{*}{$\begin{array}{c}\mathrm{H}_{2} \mathrm{O} \\
\text { Mixing } \\
\text { Ratio } \\
40 \mathrm{~km}\end{array}$} & \multirow[b]{2}{*}{$\begin{array}{l}\text { Calculation } \\
\text { Type }\end{array}$} \\
\hline & & $\begin{array}{l}\text { Solar Cycle } \\
\text { Phase }\end{array}$ & $\begin{array}{c}\text { Earth } \\
\text { Latitude }\end{array}$ & Season & & \\
\hline $\begin{array}{l}1 \\
2 \\
3 \\
4 \\
5\end{array}$ & $\begin{array}{l}30^{\circ} \mathrm{N} \text { July } \\
30^{\circ} \mathrm{N} \text { July } \\
30^{\circ} \mathrm{N} \text { July } \\
30^{\circ} \mathrm{N} \text { July } \\
\text { midlatitude } \\
\text { spring/fall }\end{array}$ & $\begin{array}{l}\text { minimum } \\
\text { minimum } \\
\text { minimum } \\
\text { maximum } \\
\text { maximum }\end{array}$ & $\begin{array}{l}38^{\circ} \mathbf{N} \\
38^{\circ} \mathbf{N} \\
38^{\circ} \mathbf{N} \\
38^{\circ} \mathbf{N} \\
32^{\circ} \mathbf{N}\end{array}$ & $\begin{array}{l}\text { July } \\
\text { July } \\
\text { July } \\
\text { July } \\
\text { May }\end{array}$ & $\begin{array}{l}7 \mathrm{ppm} \\
7 \mathrm{ppm} \\
5 \mathrm{ppm} \\
7 \mathrm{ppm} \\
7 \mathrm{ppm}\end{array}$ & $\begin{array}{l}\text { diurnal average } \\
\text { diurnal } \\
\text { diurnal average } \\
\text { diurnal average } \\
\text { diurnal average }\end{array}$ \\
\hline
\end{tabular}

TABLE 2. Models Used in Calculations

"U.S. Standard Atmosphere Supplements (1966). 


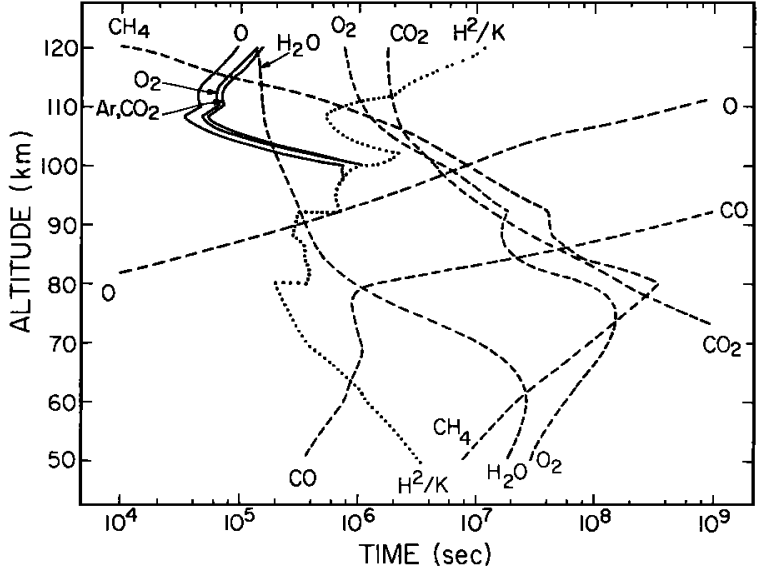

Fig. 1. A comparison of the model 1 results for the chemical lifetimes (dashed line) of major middle atmosphere species and the timescales for transport due to eddy diffusion (dotted line) and molecular diffusion (solid line). The species-dependent chemical lifetime and molecular diffusion curves are labeled with the appropriate species and, in the latter case, are shown only when they are less than the eddy diffusion values.

the mesopause to bring it into better agreement with the Aladdin 74 observations [Weeks et al., 1978].

In the lower thermosphere, the results of model 1 using the best fit eddy diffusion profile (Figure 2) agree well with the observations as is seen in Figure 3. As shown in Figure 4a, above $90 \mathrm{~km}$ the production of atomic $\mathrm{O}$ due to $\mathrm{O}_{2}$ photodissociation (reactions 1 and 2, Table 1) is significantly larger than the chemical loss of odd oxygen (atomic $O$ being the most abundant species) due to reactions 12 and 17 (Table 1). This results in an increasing downward flux of atomic $\mathrm{O}$ (Figure $4 b$ ). On the other hand, the profiles of $\mathrm{O}_{2}$ and $\mathrm{CO}_{2}$ reflect the upward motion of these species. The derived value of $K(z)$ at the homopause is thus constrained by two opposing effects: if $K(z)$ is significantly reduced, the downward flow of atomic $O$ is reduced and its concentration at $120 \mathrm{~km}$ is increased, but the upward flow of $\mathrm{O}_{2}, \mathrm{CO}_{2}$, and $\mathrm{Ar}$ is also reduced and their values at $120 \mathrm{~km}$ decrease. Complementary profile variations will occur if $K(z)$ is significantly increased instead. Thus the resulting $K(z)$ profile gives the best agreement between measured and calculated thermospheric $\mathrm{O}_{2}, \mathrm{CO}_{2}$, and $\mathrm{Ar}$ profiles and the atomic $O$ profile above $105 \mathrm{~km}$. The model results systematically lie on the high side of the uncertainty range for all the species above $110 \mathrm{~km}$. This may be explained by dynamical perturbations of the atmosphere-tidal and internal gravity waves - that our numerical model does not account for, but which may influence the atmospheric structure [Trinks et al., 1978]. Atomic O may be particularly sensitive to tidal effects as demonstrated by the model calculations of Forbes [1978], which show significant tidal variability for all species around $120 \mathrm{~km}$. But in the case of atomic $O$ there is a maximum variation of $\sim 20 \%$ in both diurnal and semidiurnal modes that both peak in mid to late afternoon (precisely the time of the Aladdin 74 observations).

The atomic $O$ peak at $98 \mathrm{~km}$ is an important feature resulting from transport in the lower thermosphere. If $K(z)$ were constant above $90 \mathrm{~km}$ at a value of $1 \times 10^{6} \mathrm{~cm}^{2} \mathrm{~s}^{-1}$, all species (including atomic 0 ) would monotonically decrease above this level. The only way to produce the atomic $O$ peak with the right magnitude at the right altitude is to introduce a small $K(z)$ for the range $92-98 \mathrm{~km}$. The atomic $O$ which otherwise would flow down to the mesopause is stopped at $98 \mathrm{~km}$ and accumulates. The observed rapid decrease in atomic $O$ below the peak fixed the value of $K(90)$.

The magnitude of eddy diffusion below $90 \mathrm{~km}$ has no effect on the $\mathrm{O}_{2}, \mathrm{CO}_{2}$, and $\mathrm{Ar}$ profiles in the lower thermosphere. However, the flow of atomic $O$ down to the mesopause (as reflected in the abundance of $\mathrm{O}_{3}$ ) and the upward transport of $\mathrm{H}_{2} \mathrm{O}$ will be affected by the value of $K(z)$ for the range 80-90 $\mathrm{km}$. The chemical lifetime of $\mathrm{H}_{2} \mathrm{O}$ is only a little longer than $\tau_{E}(z)$, so the gradient of the $\mathrm{H}_{2} \mathrm{O}$ mixing ratio at the mesopause (Figure $5 b$ ) is sensitive to the values of $\tau_{E}(z)$. The eddy diffusion profile was chosen to minimize the $\mathrm{O}_{3}$ concentration at the mesopause minimum (M. Allen and Y. L. Yung, in preparation, 1981), but at the same time the resulting value for $\mathrm{H}_{2} \mathrm{O}$ at $90 \mathrm{~km}$ remaining consistent (which it does) with the unpublished result of $H$. Trinks from the Aladdin 74 flight (Figure 5b). The Trinks measurement marginally excludes the result for a drier atmosphere. The difference between the profiles for solar minimum and maximum conditions demonstrates the need for precise model simulation of observing conditions when a good theoretical fit to measurements is being attempted.

The mesospheric portion of the derived eddy diffusion profile was constrained to intersect the stratospheric eddy diffusion profile recommended by Hudson [1977] at the stratopause $(50 \mathrm{~km})$. Since the magnitude of the $\mathrm{O}_{3}$ minimum at the mesopause is inversely related to the rate of upward transport of $\mathrm{H}_{2} \mathrm{O}$ in the mesosphere (M. Allen and Y. L. Yung, in preparation, 1981), the derived eddy diffusion coefficient increases with altitude to maximize the upward flux of $\mathrm{H}_{2} \mathrm{O}$ to the mesopause. The chemical lifetime of $\mathrm{H}_{2} \mathrm{O}$ places a maximum value on $K(2)$ above which the rate of $\mathrm{H}_{2} \mathrm{O}$ transport cannot be effectively increased [Hunten, 1975]. In Figure 5b, the $\mathrm{H}_{2} \mathrm{O}$ profile of model 1 is seen to lie between the data of Waters et al. [1980] and Radford et al. [1977].

Observations of upper atmosphere $\mathrm{CO}$ can be used to check the $K(z)$ profile derived for the mesosphere. The chemical lifetime of $\mathrm{CO}$ below $80 \mathrm{~km}$ is sufficiently close to the transport timescales so that the $\mathrm{CO}$ vertical profile reflects the magnitude of mesospheric eddy diffusion. Above $\sim 55 \mathrm{~km}$, the primary source of $\mathrm{CO}$ is the photodissociation of $\mathrm{CO}_{2}$ (reaction 34, Table 1). At the stratospause, the dominant local production source becomes the oxidation of methane by odd oxygen species $\left(\mathrm{OH}, \mathrm{O}, \mathrm{O}\left({ }^{\mathrm{l}} \mathrm{D}\right)\right.$, reactions $35-37$ in Table 1). (Addi-

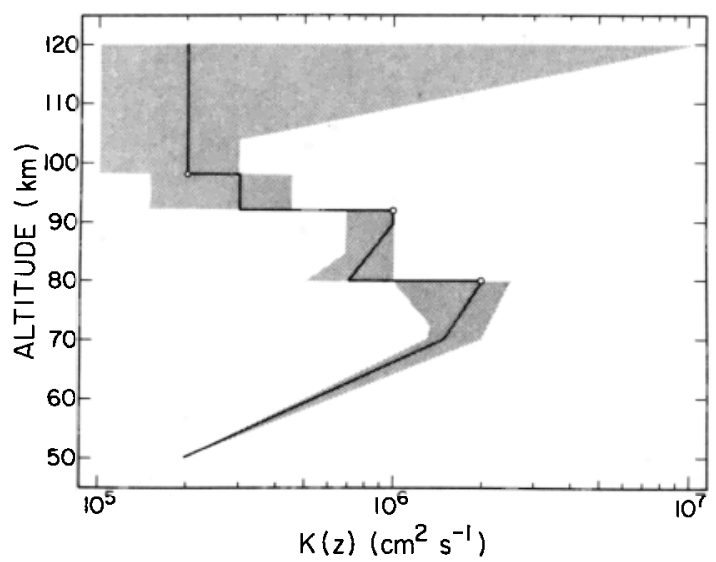

Fig. 2. The best fit eddy diffusion profile derived in this paper (solid line) and a range of values (shaded area) for which the model results are still in relatively good agreement with the observations. 


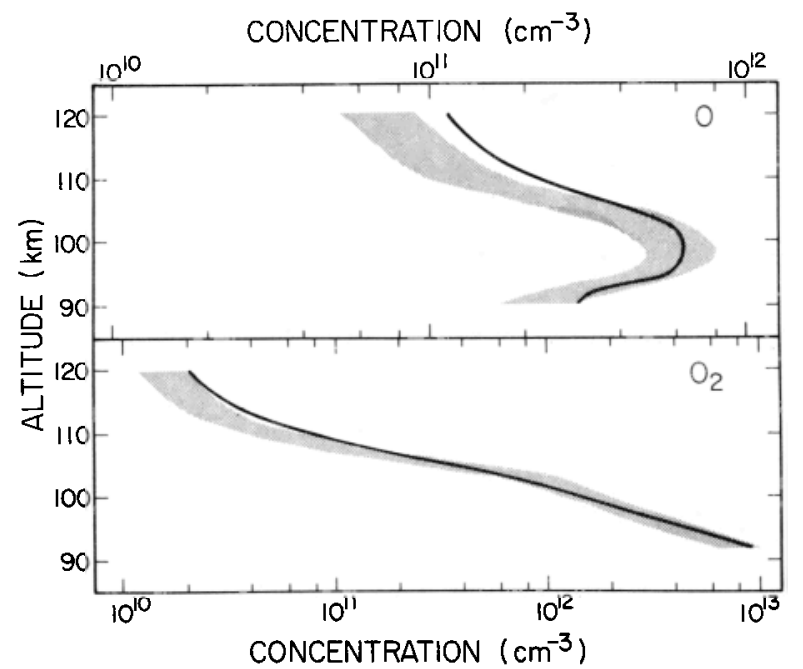

$\boldsymbol{A}$

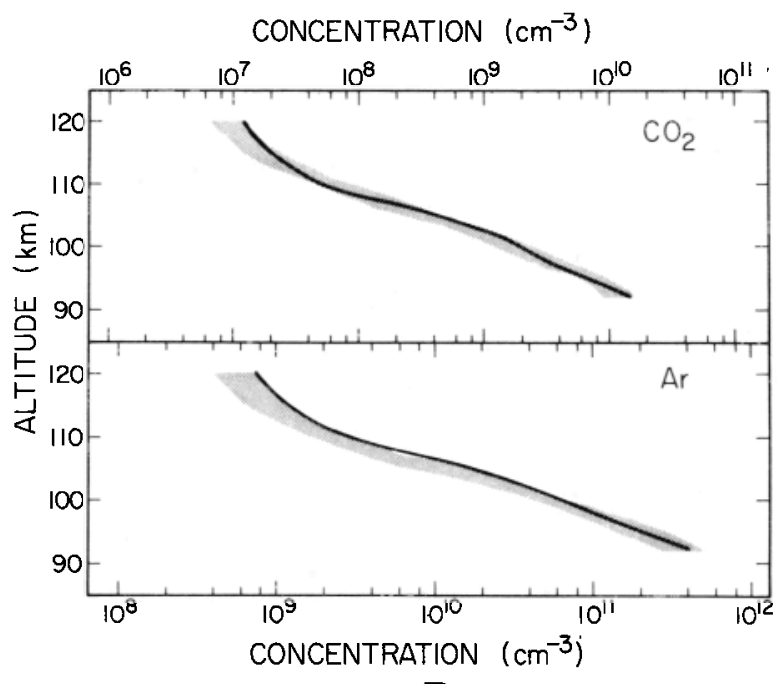

B

Fig. 3. A comparison of model 1 calculations (solid lines) and Aladdin 74 mass spectral observations with measurement uncertainties included (shaded area) for (a) atomic $\mathrm{O}$ and $\mathrm{O}_{2}$ and (b) $\mathrm{CO}_{2}$ and $\mathrm{Ar}$.

tional destruction of $\mathrm{CH}_{4}$ by $\mathrm{Cl}$ is minimal and has not been includer.) There are a number of intermediate steps in each oxidation sequence [Wofsy et al., 1972; Wofsy, 1976] but the net result for the conditions of the upper atmosphere can be well represented by the reaction sequences in Table 1 (with the assumption that the initial reaction with $\mathrm{CH}_{4}$ is the ratedetermining step). There is only one chemical loss mechanism known to be important for $\mathrm{CO}$ in the upper atmosphere: oxidation by $\mathrm{OH}$ to $\mathrm{CO}_{2}$ (reaction 38, Table 1). The production and loss rates for $\mathrm{CO}$ due to these reactions are shown in $\mathrm{Fig}$ ure $6 a$. Above the mesopause, chemical loss is negligible, resulting in a downward flux of CO (Figure $6 b$ ). Below $75 \mathrm{~km}$, $\mathrm{CO}$ is also not in photochemical equilibrium, but in this region the chemical loss rate is larger than the production rate. The magnitude of this chemical loss is proportional to the abundance of $\mathrm{OH}$. The only available measurements of mesospheric OH (Anderson [1971], updated by Hudson and Reed [1979]) are shown in Figure 5a. The OH profiles from models 1-4 are presented to demonstrate the sensitivity of the OH profile to the phase of the solar cycle and the amount of mesospheric $\mathrm{H}_{2} \mathrm{O}$. The model 1 diurnally averaged profile is seen to be close to the profile of the model 2 diurnal calculation for 1816 local time, the time of Anderson's observations. The fact that all the $\mathrm{OH}$ profiles are approximately the same demonstrates that the OH distribution depends most on the model

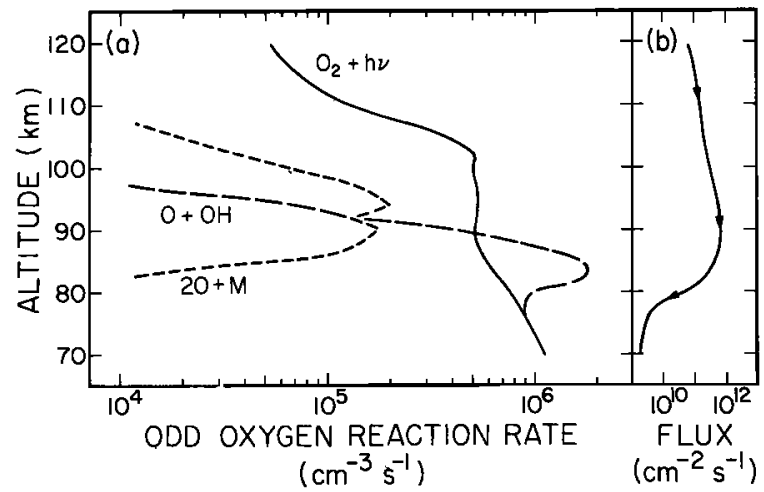

Fig. 4. Model 1 odd oxygen results. (a) Odd oxygen production (solid line) and loss rates (dashed line). (b) Atomic $O$ vertical flux. kinetics. So the agreement with the Anderson measurements confirms the basic reaction scheme.

As the mesosphere is a sink for $\mathrm{CO}$, the magnitude of the downward transport of CO strongly controls the mesospheric CO profile. One way of testing the best fit eddy diffusion profile is by comparing the model mesospheric $\mathrm{CO}$ profiles with observational results. W. J. Wilson has kindly communicated to us his accurately calibrated measurement of mesospheric CO emission at $115 \mathrm{GHz}(J=1-0$ transition) madẽ in May 1979 at Kitt Peak, Arizona $\left(32^{\circ} \mathrm{N}\right)$. We used the $\mathrm{CO}$ results of model 5 , which best simulates the circumstances of his observation, to calculate a $\mathrm{CO}$ emission profile for comparison with his observations. The results are shown in Figure 7. Figure 8 shows the $\mathrm{CO}$ mixing ratio profile from model 5. Considering

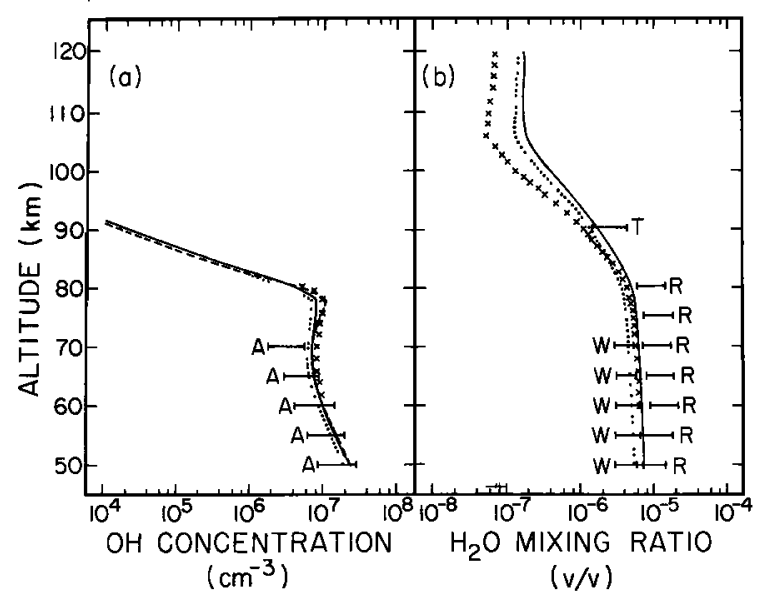

Fig. 5. (a) The altitude profiles of $\mathrm{OH}$ calculated in model 1 (solid line), model 2 for 1816 LST (dashed line), model 3 (dotted liné), and model 4 (crosses) compared with the measurements of Anderson [1971] as updated in Hudson and Reed [1979] (A). (b) The altitude profiles of $\mathrm{H}_{2} \mathrm{O}$ calculated in models 1,3 , and 4 (same symbols as in Figure 5a) compared with the observations of Radford et al. [1977] (R), Waters et al. [1980] (W), and $\mathrm{H}$. Trinks (private communication, 1979) (T). Recent observations by S. Deguchi and D. $\Theta$. Muhleman (private communication, 1980) yield a constant mixing ratio in accord with the Waters et al. [1980] result, but can be better explained by â varying mixing ratio profile close to that of model 3. 
the estimated calibration uncertainty and the peak-to-peak noise in Wilson's observational data of $\sim 0.08 \mathrm{~K}$, the $\mathrm{CO}$ emission line synthesized from the model 5 results and the observed emission line agree to within the observational uncertainty. The CO mixing ratio reported by Waters et al. [1976] is plotted in Figure 8 and is seen to be a factor of 2-3 higher than the model 5 profile for altitudes below $90 \mathrm{~km}$. As a result, a synthetic $\mathrm{CO}$ emission profile calculated with the Waters et al. [1976] mixing ratio is twice as large as the observed profile. Since the emission at line center is most sensitive to the $\mathrm{CO}$ abundance in the $70-90 \mathrm{~km}$ range, the agreement between the observed and model 5 emission suggests that the eddy diffusion profile below $90 \mathrm{~km}$ as derived from early summer 1974 (solar minimum) observations is not significantly different from that in late spring 1979 (near solar maximum).

The best fit eddy diffusion profile which we have derived is shown as a solid line in Figure 2 and is summarized in Table 3. The shaded area in Figure 2 defines a range of values for the eddy diffusion profile which still would result in model profiles in reasonable agreement with the observational data.

\section{Discussion}

Considering that the vertical profiles of several of our tracer species reflect chemistry in addition to transport, it is remarkable that a single set of species-independent variables- $K(z)-$ could be determined which allows the model profiles to match observations so well. This is indeed surprising since many speculate that one-dimensional models cannot be expected to be accurate, that there are important dynamical processes which are not included, therefore limiting the validity of the models. Frederick [1979] shows how winds and internal gravity waves could result in large horizontal variations in the abundances of trace thermospheric species, which certainly would be seen in observations deviating from mean values predicted by the one-dimensional models. However, if the net effect of all of these short-term dynamical perturbations systematically remains constant over the lifetime of the measured species, this net effect may still be validly parametrized as eddy diffusion.

Out best fit eddy diffusion profile above $90 \mathrm{~km}$ is close to the value of Hunten [1975] derived from the homopause altitude obtained from Ar measurements [von Zahn, 1970]. The profile below $80 \mathrm{~km}$ is actually twice the values of Hunten [1975], as was suggested for the stratosphere by Hudson [1977].

In Figure 9, the best fit eddy diffusion profile is compared with eddy diffusion coefficients derived from direct observations of atmospheric motions. Below $60 \mathrm{~km}$, our eddy diffusion profile is in good agreement with the $40^{\circ} \mathrm{N}$ summer values of Nastrom and Brown [1978], who analyzed rocketsonde data. Keneshea et al. [1979] calculated a minimum eddy diffusion profile for below $90 \mathrm{~km}$ using turbulent heat transfer theory. As such, there is no conflict between their profile and our derived profile, for below $80 \mathrm{~km}$ the slopes are the same but ours is offset by a factor of two. The magnitude $\left(2 \times 10^{6} \mathrm{~cm}^{2}\right.$ $\mathrm{s}^{-1}$ ) and altitude $(80 \mathrm{~km})$ of the maximum eddy diffusion coefficient is in surprising agreement with the independently calculated theoretical value of Lindzen [1980] for a summer atmosphere. Above $90 \mathrm{~km}$, the eddy profile of Keneshea et al. [1979] was determined from observations of chemical trails [Zimmerman and Trowbridge, 1973]. Eddy diffusion coefficients for above $95 \mathrm{~km}$ have also been derived from radio and

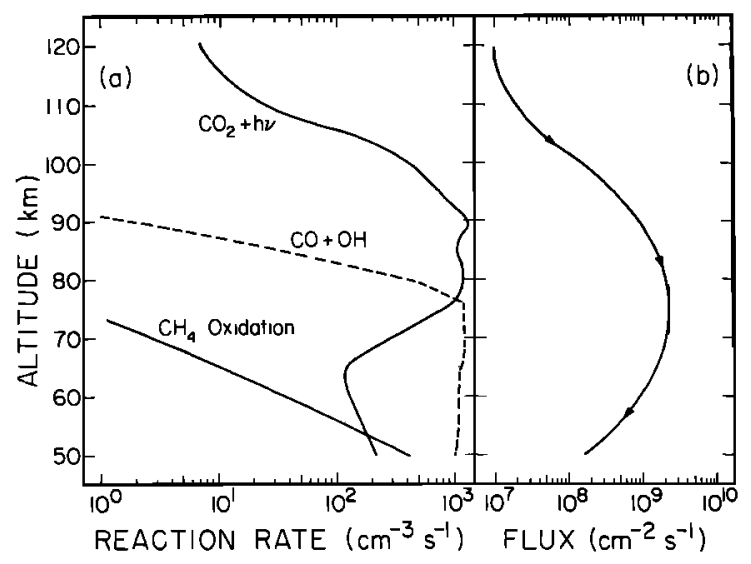

Fig. 6. Model 5 CO results. (a) Production (solid lines) and loss rates (dashed line). (b) Vertical flux.

radar observations of ionospheric turbulence [Ebel, 1978; $A l$ cayde et al., 1979]. Where seasonal variations were reported, the summer observations were chosen for Figure 9. These latter 'direct' measurements of $K(z)$ are much higher than our derived values, but are in some agreement with the widely varying numbers of Keneshea et al. [1979]. As this is the region in which molecular diffusion comes to dominate mass transport, our model calculations become less useful for deriving $K(z)$, but model 1 runs using such high values for $K(z)$ at the homopause yield results that do not agree well with observations. It should be noted that the $K(z)$ deduced from direct observations refer to instantaneous values, whereas the $K(z)$ of the current study is averaged over the lifetime of the tracer species.

A very interesting feature in our best fit eddy diffusion profile is the 'stagnant' layer extending from 92 to $98 \mathrm{~km}$, which does not affect the $\mathrm{O}_{2}, \mathrm{Ar}$, and $\mathrm{CO}_{2}$ concentrations at $120 \mathrm{~km}$ but is needed to produce the atomic $O$ peak at $98 \mathrm{~km}$. The large precipitous decrease of our profile at $92 \mathrm{~km}$ and the chemical trail result of Keneshea et al. [1979] are in very good agreement. Because this stagnant layer exists in their eddy diffusion profile, the model results of Keneshea et al. [1979] also yield an atomic $O$ peak around $95 \mathrm{~km}$. As the chemical trail data used by Keneshea et al. [1979] came from the Aladdin 1 experiment in November 1970 and the observational data we used from Aladdin 74 (June 1974), a stagnant layer in this part of the thermosphere appears to be a frequently recurrent, if not persistent, feature. It may indeed be a persistent feature, independent of season or solar cycle, since the mass spectra of Scholz and Offermann [1974] (March 1972), the resonance lamp observations of Dickinson et al. [1974] (April 1974), Thomas et al. [1979] (September 1975), and Howlett et al. [1980] (December 1975), and the airglow measurements of Wasser and Donahue [1979] (November 1969) and Witt et al. [1979] (March 1975) all show an atomic O peak around this altitude. Moreover, Donahue and Carignan [1975] in their analysis of OGO 6 atomic $O$ nightglow photometric data suggest a low value for $K(z)$ in the lower thermosphere. The elucidation of a detailed physical mechanism that would generate this thermospheric structure is beyond the scope of this paper. Various theoretical dynamics models do exist in the literature, for example, Lindzen [1971]. However, this stagnant layer may simply refiect a stable atmpsphere due to the small positive temperature gradient at the base of the thermosphere, analogous to the situation in the lower stratosphere. 


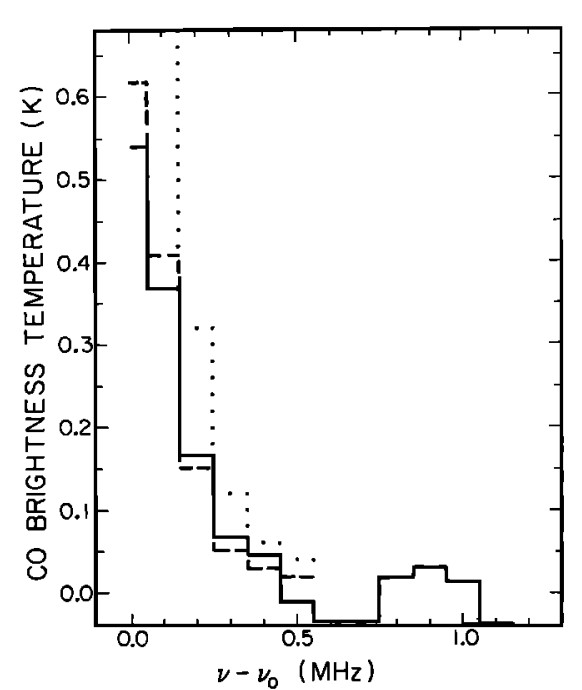

Fig. 7. A comparison of the $\mathrm{CO} J=1-0$ emission line measured by W. J. Wilson in May 1979 (solid line) and the synthetic line profiles generated using the $\mathrm{CO}$ mixing ratio distributions calculated in model 5 (dashed line) and calculated by Waters et al. [1976] from an earlier measurement (dotted line). The uncertainty in the Wilson measurement can be estimated from the baseline fluctuation $\left(\nu-\nu_{0} \geq\right.$ $0.5 \mathrm{MHz})$.

Even when the stagnant layer was included in our eddy diffusion profile, an $0 / \mathrm{O}_{2}$ concentration ratio at $120 \mathrm{~km}$ of $\sim 1$ would result if $K(z)$ above $98 \mathrm{~km}$ was significantly increased, at the same time leaving the $\mathrm{Ar} / \mathrm{N}_{2}$ concentration ratio relatively unchanged. So the thermospheric oxygen model of Colegrove et al. [1965] is accurate. However, early thermospheric mass spectroscopy did not reliably measure atomic 0 [von Zahn, 1970] and generally underestimated the atomic $O$ abundance [Keneshea et al., 1979], so the derivation of a high $K(z)$ by Colegrove et al. [1965] can now be understood.

The $\mathrm{Ar} / \mathrm{N}_{2}$ and $\mathrm{O}_{2} / \mathrm{N}_{2}$ model profiles of Keneshea et al. [1979] match the Aladdin 1 observations as well as our model profiles match the Aladdin 74 data. However, there is no contradiction between our respective eddy diffusion profiles because their eddy diffusion coefficients averaged over a scale height at the homopause is close to the value we derived. The

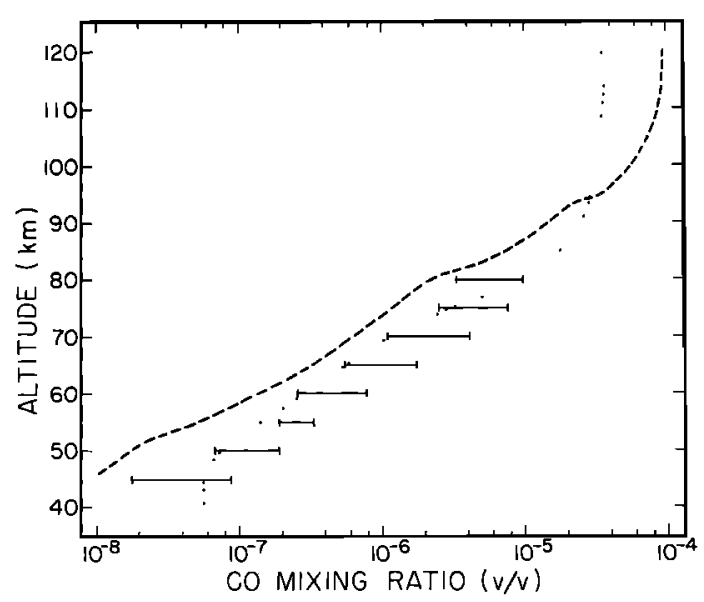

Fig. 8. The CO mixing ratio profile calculated in model 5 (dashed line) compared with the results of Waters et al. [1976] (dotted line) and Goldsmith et al. [1979] (bars). The error bars for Goldsmith et al. are the sum of the variance between the different values derived from the different rotational transitions plus the uncertainties for the values of each transition (50\% error assumed above $65 \mathrm{~km}$ ).
TABLE 3. Best Fit Eddy Diffusion Profile

\begin{tabular}{cc}
\hline Altitude Range, $\mathrm{km}$ & $K(z), \mathrm{cm}^{2} \mathrm{~s}^{-1}$ \\
\hline $50 \leq z<70$ & $2 \times 10^{5} \mathrm{e}^{(z-50) / 9.93}$ \\
$70 \leq z<80$ & $1.5 \times 10^{6} \mathrm{e}^{(z-70) / 34.8}$ \\
$80 \leq z<90$ & $7 \times 10^{5} \mathrm{e}^{(z-80) / 28.0}$ \\
90 & $1 \times 10^{6}$ \\
$92-98$ & $3 \times 10^{5}$ \\
$z \geq 100$ & $2 \times 10^{5}$ \\
\hline
\end{tabular}

discrepancy between their $\mathrm{Q} / \mathrm{O}_{2}$ model results and the Aladdin 1 observations is most likely due to measurement error.

The earlier thermospheric models of Hunt [1971, 1973] and Thomas and Bowman [1972] yield values of $\sim 1$ for the $120 \mathrm{~km}$ $O / \mathrm{O}_{2}$ concentration ratio and no atomic $O$ peak at $\sim 98 \mathrm{~km}$. This is due to a systematic use of a large $K(z)$ above $100 \mathrm{~km}$ and a smoothly varying $K(z)$ profile below. Thomas and Bowman [1972] do note the need for a slower eddy diffusion profile if they were to produce a large $O / \mathrm{O}_{2}$ ratio at $120 \mathrm{~km}$ to be consistent with the results of more accurate thermospheric mass spectroscopy just becoming available at the time of their paper. However, an atomic $O$ peak at $\sim 100 \mathrm{~km}$ is seen in the results of Koshelev [1976] when the eddy diffusion profile that decreases rapidly at $\sim 95 \mathrm{~km}$ is used (i.e., the atmosphere is stagnant above), but he does not state any causal relationship. Moreels et al. [1977] produce an atomic O peak at $\sim 90 \mathrm{~km}$, but they do not discuss the significance of this feature and the $K(z)$ profile used in generating this result is not clearly stated.

The decrease in the $\mathrm{H}_{2} \mathrm{O}$ mixing ratio from the stratopause to the lower thermosphere reflects the intensity of the solar radiation field (see Figure $5 b$ for an illustration of the difference due to the phase of the 11-year solar cycle) and the magnitude of eddy diffusion in the upper mesosphere. The $\mathrm{H}_{2} \mathrm{O}$ gradient in the Keneshea et al. [1979] model is similar to ours since the mean transport time at the relevant altitude in both cases is similar. On the other hand, Hunt [1971, 1973] has too sharp a gradient, which is probably due to his slow eddy diffusion profile at $80 \mathrm{~km}$ (upward transport not being able to replenish the $\mathrm{H}_{2} \mathrm{O}$ lost due to photodissociation). The mesospheric $\mathrm{H}_{2} \mathrm{O}$ gradients of Thomas and Bowman [1972], Koshelev [1976], and Moreels et al. [1977] are approximately the same as ours, but the combinations of solar flux and transport differ among the papers so the explanation of the results is not clear.

Figure 7 demonstrates that the differences between our model CO mixing ratio profile and that of Waters et al. [1976] (see Figure 8) would result in significantly different rotational line spectra. (The CO microwave line measured by Waters et al. [1976] is almost twice as strong as the recent unpublished measurement by $\mathrm{W}$. J. Wilson; the difference may be due to long term variations in the mesospheric $\mathrm{CO}$ profile.) The results of Goldsmith et al. [1979] would also produce CO spectra different from what W. J. Wilson observed. An intercomparison of the results of our models 1-5 reveals that this discrepancy cannot be accounted for by seasonal, solar cycle, or $\mathrm{H}_{2} \mathrm{O}$ content effects. So the variance between our $\mathrm{CO}$ mixing ratio profile and the profiles derived from published observations may be due to measurement errors, errors in the postobservation deconvolution analysis, or differences in the transport rates at the times of the observations.

A major difference between our $\mathrm{CO}$ model calculations and previous work, besides the use of different eddy diffusion rates, is the temperature dependence of our $\mathrm{CO}_{2}$ cross sections. In the thermosphere, as the temperature increases rap- 


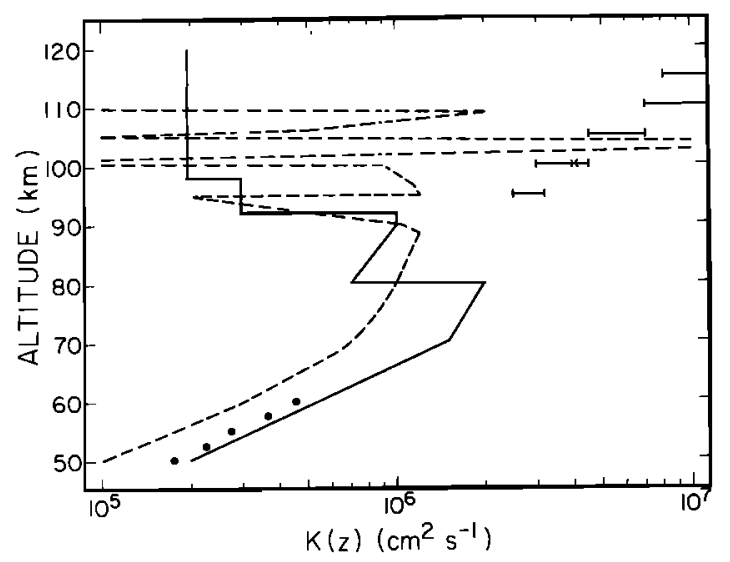

Fig. 9. The best fit eddy diffusion profile derived in this paper (solid line) compared with the eddy diffusion profile used by $\mathrm{Ke}$ neshea et al. [1979] (dashed line) and eddy diffusion coefficients derived by Nastrom and Brown [1978] from rocketsonde data (dots) and by Alcayde et al. [1979] (bars) and Ebel [1978] (X) from ionospheric turbulence measurements.

idly, some $\mathrm{CO}_{2}$ cross sections will increase, resulting in a larger $\mathrm{CO}$ production rate than would occur otherwise. At the mesopause, where the temperature is as much as $100^{\circ}$ below the temperature at which the cross sections were measured, the $\mathrm{CO}$ production rate will be reduced by this effect. In the thermosphere, this $\mathrm{CO}$ production rate temperature dependence, along with the choice of appropriate $\mathrm{CO}$ and $\mathrm{CO}_{2}$ boundary conditions, results in the $\mathrm{CO}$ profile crossing the $\mathrm{CO}_{2}$ profile at $109 \mathrm{~km}$ (model l). The crossing point in the solar maximum calculation (model 4) is $2 \mathrm{~km}$ lower.

Most of the previously published mesospheric carbon chemistry models yield $\mathrm{CO}$ profiles quite different from ours. The pioneering model of Hays and Olivero [1970] gives too much $\mathrm{CO}$ in the lower mesosphere by a factor of $10-100$. The fact that they find $\mathrm{CO}$ to be in photochemical equilibrium below $70 \mathrm{~km}$ (cf. our Figure 6) must mean that their $\mathrm{CO}_{2}$ photodissociation rate is too large (as described above) and/or their OH concentrations too small, both effects leading to an increase in the predicted CO abundance. The Wofsy et al. [1970] CO profile is smaller than ours above the mesopause, which may result from their using a $K(z)=5 \times 10^{6} \mathrm{~cm}^{2} \mathrm{~s}^{-1}$ above 70 $\mathrm{km}$, causing $\mathrm{CO}$ to be moved too rapidly through this region. As the $\mathrm{CO}$ peak brightness temperature is most sensitive to the 70-90 km CO distribution, the Wofsy et al. [1972] profile would yield a $115 \mathrm{GHz} \mathrm{CO}$ microwave emission line much weaker than observed (the microwave line calculated for the Wofsy et al. [1972] CO profile is given by Waters et al. [1976]). Since the models of Hunt [1973], Whitten et al. [1973], and Shimazaki and Cadle [1973] have less mesospheric $\mathrm{OH}$ than ours, their mesospheric CO is systematically greater. Also, their temperature, independent $\mathrm{CO}_{2}$ cross sections contribute to this result. In addition, the $\mathrm{CO}-\mathrm{CO}_{2}$ crossing altitude is too high in Hunt [1973] and Shimazaki and Cadle [1973].

\section{CONCLUSIONS}

The vertical distributions of long-lived species in the terrestrial mesosphere and lower thermosphere are controlled by several factors: kinetics, solar radiation, and vertical transport. We have shown that an eddy diffusion profile can be derived that will give good agreement between predicted and observed distributions for various species if the solar flux values for the appropriate phase of the 11-year solar cycle and the kinetics are carefully modeled. This eddy diffusion profile provides information on the mean dynamical structure of the middle atmosphere.

Since we utilized only a limited number of observations, the eddy diffusion coefficients presented in this paper may only be appropriate for midlatitudes in late spring and early summer, but are possibly independent of the phase of the solar cycle. Other sets of rocket mass spectrometer data are available (C. R. Philbrick, private communication, 1980; D. Offermann, private communication, 1980), which could be analyzed by the approach used in this paper to yield eddy diffusion profiles for various seasons and latitudes. Indeed, extensive analysis of oGo 6 O I green line nightglow photometer data [Was-

TABLE 4. Thermospheric Temperature Profiles Used in Model Calculations

\begin{tabular}{|c|c|c|c|c|}
\hline \multirow[b]{2}{*}{$\begin{array}{c}\text { Altitude, } \\
\text { km }\end{array}$} & \multirow[b]{2}{*}{$\begin{array}{c}\text { Hydrostatic } \\
\text { Calculation, } \\
\text { K }\end{array}$} & \multirow[b]{2}{*}{$\begin{array}{l}\text { Millstone } \\
\text { Hill Data, } \dagger \\
\text { K }\end{array}$} & \multicolumn{2}{|c|}{ Model Profiles $\ddagger$} \\
\hline & & & $\begin{array}{c}30^{\circ} \mathrm{N} \\
\text { July, } \\
\mathbf{K}\end{array}$ & $\begin{array}{c}\text { Midlatitude } \\
\text { Spring/Fall, } \\
\text { K }\end{array}$ \\
\hline 80 & & & 181 & 191 \\
\hline 82 & & & 173 & 191 \\
\hline 84 & & & 173 & 191 \\
\hline 86 & & & 173 & 191 \\
\hline 88 & & & 173 & 191 \\
\hline 90 & & & 175 & 191 \\
\hline 92 & & & 180 & 192 \\
\hline 92.5 & 156 & & & \\
\hline 94 & & & 185 & 194 \\
\hline 95 & 166 & & & \\
\hline 96 & & & 190 & 196 \\
\hline 97.5 & 170 & & & \\
\hline 98 & & & 195 & 198 \\
\hline 100 & 161 & & 200 & 200 \\
\hline 102 & & & 210 & 210 \\
\hline 102.5 & 141 & & & \\
\hline 104 & & & 220 & 220 \\
\hline 105 & 166 & & & \\
\hline 105.7 & & 186 & & \\
\hline 106 & & & 235 & 235 \\
\hline 107.5 & 236 & & & \\
\hline 108 & & & 255 & 255 \\
\hline 108.7 & & 247 & & \\
\hline 110 & 329 & & 275 & 275 \\
\hline 111.7 & & 280 & & \\
\hline 112 & & & 305 & 305 \\
\hline 112.5 & 403 & & & \\
\hline 114 & & & 335 & 335 \\
\hline 114.7 & & 353 & & \\
\hline 115 & 457 & & & \\
\hline 116 & & & 365 & 365 \\
\hline $\begin{array}{l}117.5 \\
117.7\end{array}$ & 483 & 390 & & \\
\hline 118 & & & 390 & 390 \\
\hline 120 & 488 & & 425 & 425 \\
\hline 120.7 & & 414 & & \\
\hline 122 & & & 440 & 440 \\
\hline 123.7 & & 430 & & \\
\hline 124 & & & 460 & 460 \\
\hline 125 & 475 & & & \\
\hline 126 & & & 490 & $\begin{array}{l}490 \\
518\end{array}$ \\
\hline $\begin{array}{l}128 \\
129.7\end{array}$ & & 530 & 518 & 518 \\
\hline $\begin{array}{l}129.1 \\
130\end{array}$ & 471 & & 548 & 548 \\
\hline
\end{tabular}

*Trinks et al. [1978] total density and mass density data used. $\dagger$ Average of Millstone Hill observations at 2002 and 2035 UT, June 29, 1974 (W. Oliver, private communication, 1980).

¡Below $90 \mathrm{~km}$, close to the tabulations in the 1966 U.S. Standard Atmosphere Supplements. 
ser and Donahue, 1979, and references therein] suggests significant latitudinal variation in thermospheric transport.

In addition, it would be valuable to have a long-term program of regularly conducted simultaneous observations of trace species profiles which would allow monitoring of variations in the chemical and dynamical nature of the mesosphere and lower thermosphere. The $\mathrm{O} / \mathrm{O}_{2} / \mathrm{N}_{2}$ group is important for measuring $K(z)$ at the homopause and in the lower thermosphere region just below. If measurements sensitive to the thermospheric CO could be made, variations in the vertical profile of the $\mathrm{CO} / \mathrm{CO}_{2}$ ratio would also reflect thermal structure and radiation field changes. As mesospheric $\mathrm{O}_{3}$ concentrations reflect the magnitude of the downward flux of atomic $O$ from the thermosphere and the upward transport of $\mathrm{H}_{2} \mathrm{O}$ from the stratopause, simultaneous radio observations of $\mathrm{H}_{2} \mathrm{O}$, $\mathrm{O}_{3}$, and $\mathrm{CO}$ could be used to separate the effects of diurnal chemistry and systematic changes in the radiation field and eddy diffusion rate below $90 \mathrm{~km}$. Of these various group measurement programs, the last set of observations can be instituted most easily since the necessary technology is currently available.

\section{APPENDIX: DERIVATION OF TEMPERATURE Profile ABOVE $80 \mathrm{KM}$}

We calculated a temperature profile for the atmosphere above $90 \mathrm{~km}$ at the time of the Trinks et al. [1978] rocket flight using the total density and mass density reported by Trinks et al. and assuming that the atmosphere was hydrostatic. The results of this calculation are presented in Table 4 along with the incoherent scatter radar data obtained at Millstone Hill simultaneous with the Aladdin 74 rocket flight (W. Oliver, private communication, 1980). Above $110 \mathrm{~km}$, the Millstone Hill temperature profile is much closer to the 1966 U.S. Standard Atmosphere Supplements (USSAS) $30^{\circ} \mathrm{N}$ July profile than is the profile derived from the hydrostatic calculation. Below $105 \mathrm{~km}$ there are no radar results; the hydrostatic temperatures show wavelike structure and are significantly cooler than the 1966 USSAS profiles. This probably reflects the perturbed nature of the atmosphere at the time of the rocket flight [Trinks et al., 1978]. Since the lifetimes of the species we are considering in this paper are longer than the diurnal period, their profiles reflect the long-term average atmospheric temperature. Therefore we chose a thermospheric temperature profile that follows the Millstone Hill data above 110 $\mathrm{km}$, below which altitude we then guess at a smoothly varying profile that fits with the 1966 profile below $90 \mathrm{~km}$.

Acknowledgments. We thank S. Deguchi, C. B. Farmer, D. O. Muhleman, H. Trinks, and W. J. Wilson for communicating their results prior to publication. We also acknowledge the helpful comments of J. Anderson, W. B. DeMore, P. A. Ekstrom, D. M. Hunten, M. M. Litvak, R. Stolarski, D. F. Strobel, R. T. Watson, and the referees. This research was supported by NASA grant NSG 2229 and JPL 49649-20320-0-3270 to the California Institute of Technology. Contribution 3273 of the Division of Geological and Planetary Sciences, California Institute of Technology.

The Editor thanks P. H. G. Dickinson and J. E. Frederick for their assistance in evaluating this paper.

\section{REFERENCES}

Ackerman, M., Ultraviolet solar radiation related to mesospheric processes, in Mesospheric Models and Related Experiments, edited by G. Fiocco, pp. 149-159, D. Reidel, Hingham, Mass., 1971.

Alcayde, D., J. Fontanari, G. Kockarts, P. Bauer, and R. Bernard, Temperature, molecular nitrogen concentration and turbulence in the lower thermosphere inferred from incoherent scatter data, Ann. Geophys., 35, 41-51, 1979.

Anderson, J. G., Rocket-borne ultraviolet spectrometer measurement of $\mathrm{OH}$ resonance fluorescence with diffusive transport model for mesospheric photochemistry, J. Geophys. Res., 76, 4634-4652, 1971.

Banks, P. M., and G. Kockarts, Aeronomy, part B, p. 32, Academic, New York, 1973.

Baulch, D. L., R. A. Cox, R. F. Hampson, J. A. Kerr, J. Troe, and R. T. Watson, Evaluated kinetic and photochemical data for atmospheric chemistry, J. Phys. Chem. Ref. Data, 9, 295-471, 1980.

Carver. J. H., H. P. Gies, T. I. Hobbs, B. R. Lewis, and D. G. McCoy, Temperature dependence of the molecular oxygen photoabsorption cross section near H Lyman alpha line, J. Geophys. Res, 82, 19551960, 1977.

CIAP Monograph 1, The Natural Stratosphere of 1974, DOT-TST75-51, Climatic Impact Assessment Program, Department of Transportation, Washington, D.C., 1975.

Colegrove, F. D., W. B. Hanson, and F. S. Johnson, Eddy diffusion and oxygen transport in the lower thermosphere, J. Geophys. Res., 70, 4931-4941, 1965.

DeMore, W. B., and M. Patapoff, Temperature and pressure dependence of $\mathrm{CO}_{2}$ extinction coefficients, $J$. Geophys. Res., 77, 62916293, 1972.

Dickinson, P. H. G., R. C. Bolden, and R. A. Young, Measurement of atomic oxygen in the lower ionosphere using a rocket-borne resonance lamp, Nature, 252, 289-291, 1974.

Donahue, T. M., and G. R. Carignan, The temperature gradient between 100 and $120 \mathrm{~km}, J$. Geophys. Res., 80, 4565-4569, 1975.

Ebel, A., Estimate of macroturbulent scales in the atmosphere around $100 \mathrm{~km}$ altitude, Beitr. Phys. Atmos., 51, 31-43, 1978.

Ehhalt, D. H., L. E. Heidt, and E. A. Martell, The concentration of atmospheric methane between 44 and 62 kilometers altitude, $J$. Geophys. Res., 77, 2193-2196, 1972.

Ehhalt, D. H., L. E. Heidt, R. H. Lueb, and E. A. Martell, Concentrations of $\mathrm{CH}_{4}, \mathrm{CO}, \mathrm{CO}_{2}, \mathrm{H}_{2}, \mathrm{H}_{2} \mathrm{O}$ and $\mathrm{N}_{2} \mathrm{O}$ in the upper stratosphere, J. Atmos. Sci, 32, 163-169, 1975.

Farmer, C. B., O. F. Raper, B. D. Robbins, R. A. Toth, and C. Muller, Simultaneous spectroscopic measurements of stratospheric species: $\mathrm{O}_{3}, \mathrm{CH}_{4}, \mathrm{CO}, \mathrm{CO}_{2}, \mathrm{~N}_{2} \mathrm{O}, \mathrm{H}_{2} \mathrm{O}, \mathrm{HCL}$, and $\mathrm{HF}$ at northern and southern mid-latitudes, J. Geophys. Res., 85, 1621-1632, 1980.

Forbes, J. M., Tidal variations in thermospheric $\mathrm{O}, \mathrm{O}_{2}, \mathrm{~N}_{2}, \mathrm{Ar}, \mathrm{He}$, and H, J. Geophys. Res., 83, 3691-3698, 1978.

Frederick, J. E., Chemical response of the middle atmosphere to changes in the ultraviolet solar flux, Planet. Space Sci., 25, 1-4, 1977.

Frederick, J. E., Influence of gravity wave activity on lower thermospheric photochemistry and composition, Planet. Space Sci., 27, 1469-1477, 1979.

Frederick, J. E., Seasonal variations in high-latitude ozone and metastable molecular oxygen emissions: A theoretical interpretation, $J$. Geophys. Res., 85, 1611-1617, 1980.

Frederick, J. E., and R. D. Hudson, Atmospheric opacity in the Schumann-Runge bands and the aeronomic dissociation of water vapor, J. Atmos. Sci., 37, 1088-1098, 1980a.

Frederick, J. E., and R. D. Hudson, Dissociation of molecular oxygen in the Schumann-Runge bands, J. Atmos. Sci., 37, 1099-1106, $1980 b$.

Goldsmith, P. F., M. M. Litvak, R. L. Plambeck, and D. R. W. Williams, Carbon monoxide mixing ratio in the mesosphere derived from ground-based microwave measurements, J. Geophys. Res., 84, 416-418, 1979.

Hampson, R. F., and D. Garvin (Eds.), Reaction Rate and Photochemical Data for Atmospheric Chemistry-1977, NBS SP-513, National Bureau of Standards, Gaithersburg, Md., 1978.

Hays, P. B., and J. J. Olivero, Carbon dioxide and monoxide above the troposphere, Planet. Space Sci., 18, 1729-1733, 1970.

Howlett, L. C., K. D. Baker, L. R. Megill, A. W. Shaw, W. R. Pendleton, and J. C. Ulwick, Measurement of a structured profile of atomic oxygen in the mesosphere and lower thermosphere, $J$. Geophys. Res., 85, 1291-1296, 1980.

Hudson, R. D., Critical review of ultraviolet photoabsorption cross sections for molecules of astrophysical and aeronomic interest, $R e v$. Geophys. Space Phys., 9, 305-406, 1971.

Hudson, R. D. Absorption cross sections of stratospheric molecules, Can. J. Chem., 52, 1465-1478, 1974.

Hudson, R. D. (Ed.), Chlorofluoromethanes and the Stratosphere, 
NASA RP-1010, National Aeronautics and Space Administration, Washington, D. C., 1977.

Hudson, R. D., and E. I. Reed (Eds.), The Stratosphere: Present and Future, NASA RP-1049, National Aeronautics and Space Administration, Washington, D. C., 1979.

Hunt, B. G., A diffusive-photochemical study of the mesosphere and lower thermosphere and the associated conservation mechanisms, J. Atmos. Terr. Phys., 33, 1869-1892, 1971.

Hunt, B. G., A generalized aeronomic model of the mesosphere and lower thermosphere including ionospheric processes, J. Atmos. Terr. Phys., 35, 1755-1798, 1973.

Hunten, D. M., Vertical transport in atmospheres, in Atmospheres of Earth and the Planets, edited by B. M. McCormac, pp. 59-72, D. Reidel, Hingham, Mass., 1975.

Inn, E. C. Y., K. Watanabe, and M. Zelikoff, Absorption coefficient of gases in the vacuum ultraviolet, III, $\mathrm{CO}_{2}, J$. Chem. Phys., 21, 1648$1650,1953$.

Johnston, H. S., D. Kattenhorn, and G. Whitten, Use of excess carbon 14 data to calibrate models of stratospheric ozone depletion by supersonic transports, J. Geophys. Res., 81, 368-380, 1976.

Keneshea, T. J., S. P. Zimmerman, and C. R. Philbrick, A dynamic model of the mesosphere and lower thermosphere, Planet. Space Sci, 27, 385-401, 1979.

Klais, O., P. C. Anderson, and M. J. Kurylo, A reinvestigation of the temperature dependence of the rate constant for the reaction $\mathrm{O}+$ $\mathrm{O}_{2}+\mathrm{M} \rightarrow \mathrm{O}_{3}+\mathrm{M}$ (for $\mathrm{M}=\mathrm{O}_{2}, \mathrm{~N}_{2}$, and $\mathrm{Ar}$ ) by the flash photolysis resonance fluorescence technique, Int. J. Chem. Kinet., 12 $469-490,1980$.

Koshelev, V. V., Diurnal and seasonal variations of oxygen, hydrogen and nitrogen components at heights of mesosphere and lower thermosphere, J. Atmos. Terr. Phys., 38, 991-998, 1976.

Lii, R.-R., R. A. Gorse, M. C. Sauer, and S. Gordon, Negative activation energy for the self-reaction of $\mathrm{HO}_{2}$ in the gas phase: Dimerization of $\mathrm{HO}_{2}$, J. Phys. Chem. 83, 1803-1804, 1979.

Lindzen, R. S., Tides and gravity waves in the upper atmosphere, in Mesospheric Models and Related Experiments, edited by G. Fiocco, pp. 122-130, D. Reidel, Hingham, Mass., 1971.

Lindzen, R. S., Gravity waves, tides, and turbulence in the mesosphere, paper presented at the International Symposium on Middle Atmosphere Dynamics and Transport, Univ. of Ill., Urbana, July 30, 1980.

Liu, S. C., and T. M. Donahue, The aeronomy of hydrogen in the atmosphere of the Earth, J. Atmos. Sci, 31, 1118-1136, 1974.

Logan, J. A., M. J. Prather, S. C. Wofsy, and M. B. McElroy, Atmospheric chemistry: Response to human influence, Phil. Trans. $R$ Soc. London, 290, 187-234, 1978.

Mason, E. A., and T. R. Marrero, The diffusion of atoms and molecules, Adv. At. Mol. Phys., 6, 155-232, 1970.

McElroy, M. B., Chemical processes in the solar system: A kinetic perspective, Int. Rev. Sct. Phys. Chem. Ser. Two, 9, 127-211, 1976.

Moreels, G., G. Megie, A. Vallance Jones, and R. L. Gattinger, An oxygen-hydrogen atmospheric model and its application to the $\mathrm{OH}$ emission problem, J. Atmos. Terr. Phys., 39, 551-570, 1977.

Mount, G. H., G. J. Rottman, and J. G. Timothy, The solar spectral irradiance 1200-2550 \& at solar maximum, J. Geophys. Res., 85, 4271-4274, 1980.

NAS, Halocarbons: Effects on Stratospheric Ozone, National Academy of Sciences, Washington, D. C., 1976.

Nastrom, G. D., and D. E. Brown, Studies of stratospheric eddy transport, II, Eddy diffusion coefficients and wind statistics, 30-60 km, AFGL-TR-78-0311, Air Force Geophys. Lab., Bedford, Mass., 1978.

Nicolet, M., and W. Peetermans, Atmospheric absorption in the $\mathrm{O}_{2}$ Schumann-Runge band spectral range and photodissociation rates in the stratosphere and mesosphere, Planet. Space Sci., 28, 85-103, 1980.

Prather, M. J., Ozone in the upper stratosphere and mesosphere, $J$. Geophys. Res., in press, 1981.
Radford, H. E., M. M. Litvak, C. A. Gottlieb, E. W. Gottlieb, S. K. Rosenthal, and A. E. Lilley, Mesospheric water vapor measured from ground-based microwave observations, J. Geophys. Res., 82, 472-478, 1977.

Schmeltekopf, A. L., D. L. Albritton, P. J. Crutzen, P. D. Goldan, W. J. Harrop, W. R. Henderson, J. R. McAfee, M. McFarland, H. I. Schiff, and T. L. Thompson, Stratospheric nitrous oxide altitude profiles at various latitudes, J. Atmos. Sci., 34, 729-736, 1977.

Scholz, T. G., and D. Offermann, Measurement of neutral atmospheric composition at $85-15 \mathrm{~km}$ by mass spectrometer with cryoion source, J. Geophys. Res., 79, 307-310, 1974.

Schürgers, M., and K. W. Welge, Absorptionskoeffizient von $\mathrm{H}_{2} \mathrm{O}$ und $\mathrm{N}_{2} \mathrm{H}_{4} \mathrm{Z}$ wischen 1200 and $2000 \AA, Z$. Naturforsch. A, 23, 1508$1510,1968$.

Shimazaki, T., and R. D. Cadle, Theoretical model of vertical distributions of $\mathrm{CO}$ and $\mathrm{CH}_{4}$ in the mesosphere and upper stratosphere, J. Geophys. Res., 78, 5352-5361, 1973.

Thomas, L., and M. R. Bowman, The diurnal variations of hydrogen and oxygen constituents in the mesosphere and lower thermosphere, J. Atmos. Terr. Phys., 34, 1843-1858, 1972.

Thomas, L., R. G. H. Greer, and P. H. G. Dickinson, The excitation of the $557.7 \mathrm{~nm}$ line and Herzberg bands in the nightglow, Planet. Space Sci, 27, 925-931, 1979.

Trinks, H., and $K$. H. Fricke, Carbon dioxide concentrations in the lower thermosphere, J. Geophys. Res., 83, 3883-3886, 1978.

Trinks, H., D. Offermann, U. von Zahn, and C. Steinhauer, Neutral composition measurements between 90 - and $220-\mathrm{km}$ altitude by rocket-borne mass spectrometer, $J$. Geophys. Res., 83, 2169-2176, 1978.

von Zahn, U., Neutral air density and composition at 150 kilometers, J. Geophys. Res., 75, 5517-5527, 1970.

Wasser, B., and T. M. Donahue, Atomic oxygen between 80 and 120 $\mathrm{km}$ : Evidence for a latitudinal variation in vertical transport near the mesopause, J. Geophys. Res., 84, 1297-1309, 1979.

Watanabe, K., Ultraviolet absorption processes in the upper atmosphere, Adv. Geophys., 5, 153-221, 1958.

Waters, J. W., W. J. Wilson, and F. I. Shimabukuro, Microwave measurement of mesospheric carbon monoxide, Science, 191, 1174 $1175,1976$.

Waters, J. W., J. J. Gustincic, P. N. Swanson, and A. R. Kerr, Measurements of upper atmospheric $\mathrm{H}_{2} \mathrm{O}$ emission at $183 \mathrm{GHz}$, in Proceedings of Atmospheric Water Vapor Workshop, Academic, New York, in press, 1980.

Weeks, L. H., R. E. Good, J. S. Randhawa, and H. Trinks, Ozone measurements in the stratosphere, mesosphere, and lower thermosphere during Aladdin 74, J. Geophys. Res., 83, 978-982, 1978.

Whitten, R. C., J. S. Sims, and R. P. Turco, A model of carbon compounds in the stratosphere and mesosphere, $J$. Geophys. Res., 78 , 5362-5374, 1973 .

Witt, G., J. Stegman, B. H. Solheim, and E. J. Llewellyn, A measurement of the $\mathrm{O}_{2}\left(b^{1} \Sigma_{g}+-X^{3} \Sigma_{g}^{-}\right)$atmospheric band and the $\mathrm{O}$ I ( ${ }^{1} S$ green line in the nightglow, Planet. Space Sci., 27, 341-350, 1979.

Wofsy, S. C., Interactions of $\mathrm{CH}_{4}$ and $\mathrm{CO}$ in the Earth's atmosphere, Annu. Rev. Earth Planet. Sci., 4, 441-469, 1976.

Wofsy, S. C., and M. B. McElroy, On vertical mixing in the upper stratosphere and lower mesosphere, J. Geophys. Res., 78, 26192624, 1973.

Wofsy, S. C., J. C. McConnell, and M. B. McElroy, Atmospheric $\mathrm{CH}_{4}, \mathrm{CO}$, and $\mathrm{CO}_{2}, J$. Geophys. Res., 77, 4477-4493, 1972.

Zimmerman, S. P., and C. A. Trowbridge, The measurement of turbulent spectra and diffusion coefficients in the altitude region 95 to $110 \mathrm{~km}$, Space Res., XIII, 203-208, 1973.

(Received July 24, 1980 revised December 18, 1980; accepted December 19, 1980.) 